\title{
1 Nondestructive measurement of squalene in olive oil by near infrared 2 spectroscopy
}

3 José A. Cayuela ${ }^{1}$, Juan F. García ${ }^{2}$

$4 \quad{ }^{1}$ Instituto de la Grasa, CSIC

5 Campus of the University 'Pablo de Olavide', Ed. 46. 41013 Seville, Spain

$6 \quad{ }^{2}$ Department of Chemical Engineering, University of Seville, C/ Profesor García González, 1, 41012

7 Seville, Spain

$8 \quad{ }^{1}$ Corresponding author: jacayuela@ig.csic.es

\section{ABSTRACT}

10 This study sets the basis for developing a rapid technique for measuring olive oil 11 squalene, which is a healthy compound. This technique, based on near infrared 12 spectroscopy, is environmentally friendly. The most suitable wavelength ranges were 13 defined, studying the possible contribution from the visible spectra. For this purpose, 14 Partial Least Squares analysis was independently set up using two optical arrangements, 15 with wavelengths $350-2500 \mathrm{~nm}$ and $1100-2300 \mathrm{~nm}$. Models from only near infrared wavelengths gave the best outcomes. The external validation exercise for estimating olive oil squalene was satisfactory, with $r^{2} 0.83$ and residual predictive deviation 2.31. The results suggest the proposed technique is useful for estimating olive oil squalene content. A sorting test of olive oil in two classes according to its squalene content was carried out, with threshold in 5.0 g. $\mathrm{kg}^{-1}$, using the model built. The success of this classification was $90 \%$.

Keywords: classification; environment friendly; NIR; PLS model; ; threshold.

\section{Introduction}

Squalene (Figure 1) is a triterpene aliphatic hydrocarbon, and it was named because of its profusion in shark liver oil, its richest source, where it reaches $900 \mathrm{~g} \cdot \mathrm{kg}^{-1}$. Shark liver oil has long been used as a traditional health food in Japan, with a particular benefit for vascular health (Hamadate et al., 2015). Squalene is widely distributed in nature, especially in vegetable oils such as olive oil, palm oil, wheat-germ oil, amaranth oil, or rice bran oil (Huang, Lin, \& Fang, 2009). Therefore, by using different extraction 
31 methods, vegetables or marine animals can be suitable squalene sources (Vázquez,

32 Torres, Fornari, Senorans, \& Reglero, 2007).

33 The main part of virgin olive oil is the saponifiable fraction, a lipid matrix of 34 triglycerides, diglycerides and monoglycerides accounting for 985-995 $\mathrm{g} \cdot \mathrm{kg}^{-1}$ 35 (Civantos, 1999). Squalene is in relatively high quantities within the olive oil minor fraction. Eisner, Iverson, Mozingo, \& Firestone (1965) stated that squalene makes up around $85-90 \%$ of the hydrocarbon fraction of olive oils. Besides, it makes up $60-75 \%$ of the olive oil unsaponifiable fraction, in concentrations between 0.2 and $7.5 \mathrm{~g} \cdot \mathrm{kg}^{-1}$

39 (Tiscornia, \& Evangelisti, 1982).

Figure 1

One of the most important differences between olive oil and plant seed oils is squalene. Compared to seed oils, olive oil is an important source of squalene. In other edible vegetable oils, squalene makes up only $0.02-0.3 \mathrm{~g} \cdot \mathrm{kg}^{-1}$ (Rao, Newmark, \& Reddy, 1998). Thus, olive oil contains 7 to 300 fold more squalene than other vegetable oils and up to 5000 fold more than some vegetable foods (Liu, Ahrens, Schreibman, \& Crouse, 1976). Therefore, virgin olive oil may be a part of the human diet especially rich in squalene.

Besides, the squalene content varies widely depending on the olive oil product with a range of 2 to $7 \mathrm{~g} \cdot \mathrm{kg}^{-1}$ (Rao, Newmark, \& Reddy, 1998). A significant difference between the extra virgin class (EVOO) and the virgin class (VOO) has been reported, with the latter having more squalene than the refined olive oils (Owen, Mier, Giacosa, Hull, Spiegelhalder, \& Bartsh, 2000). Nergiz \& Çelikkale (2011) showed that refining reduces the squalene content. Furthermore, they pointed out that the major decrease in squalene in vegetable oils within the refining steps occurs during oils' deodorization.

55 Olive growing techniques (Psomiadou \& Tsimidou, 1999), olive fruit variety (Nergiz, \& 56 Ünal, 1990) and extraction (Nergiz, \& Ünal, 1990; Samaniego-Sánchez, Quesada57 Granados, López-García de la Serrana, \& López-Martínez, 2010) influence the level of squalene. Squalene acts as a weak antioxidant in olive oil (Owen, Mier, Giacosa, Hull, Spiegelhalder, \& Bartsh, 2000). Thus, Psomiadou and Tsimidou (1999) proposed that squalene contributes to olive oil stability in a small quantity, even at low temperatures. 
61 There is multiple scientific evidence on the beneficial effects that the intake of squalene

62 from food has on health (Newmark, 1997; Lasekan, Clayton, Gendron, \& Ney, 1990;

63 Smith, 2000; Ostlund, Racette, \& Stenson, 2002; Strandberg, Tilvis, \& Miettinen, 1990;

64 Smith, 2000; He, \& Corke, 2003). However, this feature of olive oil has received little attention in the market so far, since most consumers are unaware on this fact.

66

The olive oil industry has great interest on determining the quality of olive oil, using fast and reliable techniques. Besides, developing non-destructive techniques to reduce the expense of solvents and reagents is increasingly important in an international context of convergence towards environmental sustainability. Among the various nondestructive solutions to these needs, near-infrared spectroscopy (NIRS) has made major achievements. NIRS is based on multivariate models in which the spectral data correlate with the analyzed feature. It provides several important advantages, as NIRS needs no solvents or reagents, thus avoiding a major expense, while being environmentally friendly. Additionally, NIRS is a rapid, non-destructive, and potentially multi-parameter method.

Several articles on the use of NIRS and chemometrics for the analysis of different olive oil features have been published in the recent years (Nenadis \& Tsimidou, 2017). Stand out studies directed to characterizing intact olives and olive paste for optimizing the milling process (Giovenzana et al., 2017), to control the quality of olive pomace oil blended with palm oil used for deep-frying (Ben Hammouda, Zribi, Ben Mansour, Matthaus, \& Bouaziz, 2017), as well as for the authentication and detection of fraud (Karunathilaka, Kia, Srigley, Chung, \& Mossoba, 2016). Sorting olive oil based on alpha-tocopherol and total tocopherol content using NIRS has been recently reported (Cayuela \& García, 2017). The NIRS ability to analyze the major olive oil quality features has been the subject of several studies (Armenta, Garrigues, \& De la Guardia, 2007; Bendini, Cerretani, Di Virgilio, Belloni, Lercker, \& Gallina-Toschi, 2007; Conte, Brussolo, Pizzale, Carazzolo, Meurens, \& Pavan, 2003; Costa, Coelho, Gambarra, Bezerra, Harrop, \& Ugulino, 2008; Cayuela, Moreda \& García, 2013). In fact, NIRS techniques are methods for these routine analyses in a growing number of laboratories. However, the possibility of measuring squalene in olive oil by NIRS has never been reported up to date. Besides, squalene NIR absorption bands have not yet been described, to the best of our knowledge. 
93 Since the concentration of squalene varies widely among different olive oils, there is an

94 interest in the development of rapid techniques to distinguish olive oils according to its

95 content. In fact, the industry might have an interest in separating olive oils according to

96 different squalene contents. The traditional method for the analysis of squalene in olive

97 oil is GC. However, it is not usually performed in the olive oil industry, since squalene 98 is not considered in the regulation to characterize the quality or purity of olive oil

99 (European Commission, 1991). Therefore, there is a challenge on characterizing olive 100 oil regarding squalene. This work sets up the basis for developing new rapid NIRS 101 techniques for measuring olive oil squalene content. It was convenient to clarify if there 102 are any regions from the olive oil's visible spectrum contributing to model performance, 103 since pure squalene is a pale yellow liquid. The wavelengths that contribute to 104 predictive models have been defined.

\section{2. Material and Methods}

\section{2.1. Olive Oils}

107 A total set of 180 olive oil samples was made up from different origins. High quality 108 Extra Virgin Olive Oils (EVOO) were bought at olive oil specialized shops; this group 109 contributed with 32 samples, of which 27 were varietal and the remaining 5 were 110 mixtures from different varieties. These EVOO were used to elaborate 17 additional 111 coupage samples. Olive oils normally found in the market were also used; this group 112 was composed of 10 EVOOs, 40 Current Olive Oils and 25 Pomace Olive Oils. Olive 113 oil samples were provided also from a collaborator industry, contributing with 14 114 EVOOs, 25 Virgin Olive Oils and 14 Lampante Olive Oils. The characteristics of the 115 olive oil samples are shown in Table S1.

\section{2.2. Reference Analysis}

117 Squalene analysis were carried out by Gas Chromatography (GC) according to Lanzón, 118 Albi, Cert, \& Gracián (1994), modified according to Moreda, Pérez-Camino, \& Cert 119 (2004), at the Instituto de la Grasa (CSIC). Briefly, $0.1 \mathrm{mg}$ of olive oil sample was 120 disposed in a $4 \mathrm{~mL}$ screw vial, adding $1 \mathrm{~mL}$ of squalane $5 \mathrm{mg} \cdot \mathrm{mL}^{-1}$ as the internal 121 pattern. This was dissolved in heptane to complete a volume of $3 \mathrm{~mL}$ and shaked gently 122 by hand. Then $200 \mu \mathrm{L}$ of methanolic $2 \mathrm{~mol} \cdot \mathrm{L}^{-1} \mathrm{KOH}$ was added, separating the aqueous 123 and lipid phases. The upper phase was collected into a $2 \mathrm{~mL}$ chromatography vial and 
124 then injected into the GC instrument. A GC HP-5890 (Hewlet Packard Enterprise, Palo

125 Alto, USA) equipped with a split/splitless injection system was used with a SP-5 126 capillary column $5 \%$ phenylmethylsilicone fused silica, $30 \mathrm{~m}$ long, $0.25 \mathrm{~mm}$ internal

127 diameter and $0.25 \mu \mathrm{m}$ phase thickness, (Merck, Darmstadt, Germany). Flame ionization

128 detector (FID) and software Chem Station for the recording and processing of data were

129 used. The analyses were conducted with two replicates. The results were given with one

130 significant digit.

\section{$131 \quad$ 2.3. Near infra-red spectroscopy}

132 Optical arrangements NIRS and VIS/NIRS were used for defining the wavelengths 133 contributing to the predictive models, especially for clarifying the contribution from 134 visible spectra. Besides, using two different instruments allowed checking their results, 135 beyond their comparison.

136 The samples' spectra were recorded directly from olive oils without any other treatment.

137 The temperature of a body has an important influence on NIR radiation. Therefore, the 138 samples were taken from $4{ }^{\circ} \mathrm{C}$ storage and placed at room temperature in the laboratory $13918 \mathrm{~h}$ before processing. A thermostatic bath fixed at $33{ }^{\circ} \mathrm{C}$ for $30 \mathrm{~min}$ held the $20 \mathrm{~mL}$ 140 sample containers to ensure temperature stability. The averaged spectrum from two 141 measurements of 50 spectra each was registered, with each sample. The same procedure was used with both optical configurations.

143 For NIRS, the measuring mode was post dispersive transflectance. A Luminar 144 (Brimrose Inc., Maryland, USA) spectrometer was used. This instrument consists of an 145 acousto-optic tunable filter (AOTF) with InGaAs detector (1100-2300 nm). The 146 reference is automatically taken, the scanning speed is $60 \mathrm{~ms}$. The spectrometer is 147 composed of a hand-held unit, equipped with a base for laboratory use. A transflectance 148 probe accessory was used. The probe is in stainless steel, with threaded interchangeable 149 optical path. The spectra were registered as a whole, the spectral variables matching at 2 $150 \mathrm{~nm}$ intervals. The repeatability of the instrument, expressed as the standard deviation of 151 the average absorbance of five measurements of a white tile, is $6.7610^{-4}$. The signals 152 were captured using Acquire software (Brimrose Corp., Maryland).

153 The VIS/NIRS was carried out using a Labspec (Analytical Spectral Devices Inc., 154 Boulder, USA) spectrometer, with transmittance optical mode consisting of a liquid 
accessory (Ocean Optics, Largo, USA). A quartz spectrophotometric cuvette (Hellma

156 Analytics, Müllheim, Germany) with $10 \mathrm{~mm}$ path length held the samples. The whole

157 VIS/NIRS spectrum (350-2500 nm) was registered, with each spectral variable 158 corresponding to a $2 \mathrm{~nm}$ interval. The configuration for 50 spectra in continuous 159 acquisition was used. Indico Pro software (Analytical Spectral Devices Inc., Boulder,

160 USA) was used for this purpose. The spectrometer was equipped with three detectors.

161 The detector for the visible range $(350-1000 \mathrm{~nm})$ was a fixed reflective holographic

162 diode array with a sensitivity of 512 pixels. A holographic fast scanner InGaAs detector 163 cooled at $-25^{\circ} \mathrm{C}$ covered the wavelength range of $1000-1800 \mathrm{~nm}$. The same device 164 coupled with a high order blocking filter was used for the interval 1800-2500 nm. The 165 scanning speed was $100 \mathrm{~ms}$, and the acquisition processing time is less than a minute 166 for each sample, all steps included. The repeatability, expressed as the standard 167 deviation of the average absorbance of five measurements of a white tile between 350 168 and $2500 \mathrm{~nm}$, is $6.0010^{-4}$.

\subsection{Squalene spectrum}

170 Squalene of $98 \%$ purity (Merck, Darmstadt, Germany) was used as pattern to 171 characterize the squalene VIS/NIR absorption bands. The pattern spectrum was 172 registered only once using the Labspec spectrometer, by averaging four replicates. The 173 rest of the procedure was the same as previously described for olive oil samples.

\subsection{Chemometry}

175 Possible olive oil groups were analyzed by Principal Component Analysis (PCA), 176 which was also used for detecting possible spectral outliers. It was carried out from the 177 olive oils spectra of both optical configurations using The Unscrumbler 9.7 (CAMO 178 Software AS, Oslo, Norway).

179 Multivariate Partial Least Squares (PLS) analysis was performed from the spectral 180 variables of near infrared (NIRS) and visible-near-infrared (VIS/NIRS), using the 181 squalene reference analysis as a dependent variable. Transmittance spectral data were 182 averaged to $8 \mathrm{~nm}$ intervals and transformed into absorbance, then, mean normalization 183 (MN), standard normal variate normalization (SNV), and first $\left(\mathrm{D}_{1} \mathrm{SG}\right)$ and second $184\left(\mathrm{D}_{2} \mathrm{SG}\right)$ Savitzsky-Golay derivatives treatments were carried out. The PLS models for 185 squalene were built from the averaged and treated spectrum using The Unscrumbler 9.7. 
186 The full cross internal validation (FCV) procedure was used. The outliers were 187 identified as samples showing significant high residuals, according to The Unscrumbler 188 9.7. Scores plot were displayed from the regression overview plot, then selecting the 189 warning list option. The outlier list was displayed by clicking the outliers button. The 190 residuals are the differences between the predicted and the analyzed values.

191 Two independent multivariate calibration models for squalene prediction $\left(M_{1}\right.$ and $\left.M_{2}\right)$ 192 were established from the spectra obtained with NIRS and VIS/NIRS. The models' 193 principal components (PCs) were fixed after the tests using 10 PCs at first.

194 The calibration set for PLS models excluded the external validation set. It was defined 195 as one third from the 180 olive oil samples available, counting from the first. Sixty 196 samples were taken by including one of each three, from the data base of The 197 Unscrambler 9.7., in the same order as the samples were included. This validation set 198 was randomly formed, since each sample was randomly registered from a completely 199 independent olive oil batch, even when the mechanical selection by the software it was 200 not random. The squalene concentrations range in the validation set were similar to that 201 range of the calibration, as it is shown forward. Those wavelengths whose correlation

202 with squalene content was closer to zero were removed in successive PLS cycles, using 203 The Unscrambler 9.7. The variable selection ended in the last cycle that improved the 204 squared coefficient of cross validation of the calibration $\left(\mathrm{R}_{\mathrm{CV}}^{2}\right)$. This procedure provided the spectral variables selected for the PLS models. To assess model's fitness, 206 the standard error of calibration (SEC) and the closeness between their squared coefficient of calibration $\left(\mathrm{R}^{2}\right)$ and $\mathrm{R}_{\mathrm{CV}}^{2}$ were considered.

\subsection{Model Performance Assessment}

209 Calibration models were assessed by external validation exercises. For this purpose, 210 squalene content was predicted in a previously reserved set formed by 60 olive oil 211 samples which did not participate in the multivariate models. The model performance 212 was assessed according to the $r^{2}$ from the external validation exercises, which 213 corresponds to the simple linear regression between the analyzed and predicted values. 214 At the same time, the residual predictive deviation (RPD) from the external validation 215 exercise was considered. The RPD was defined (Fearn, 2002) as the ratio between the $\sigma$ 216 from the reference data of the validation set and the standard error of performance 
217 (SEP). Also, the separate analysis of the calibrations of NIRS and VIS/NIRS allowed

218 confirming their predictive ability.

\section{2.7. Classification Tests}

220 Classification tests of olive oil according to their squalene content were conducted by using the PLS model as a qualitative discrimination technique. The spectral data from only the configuration providing the best yields were used for this purpose. Two classes of olive oils, High Squalene (HS), with squalene concentration above $5.0 \mathrm{~g} \cdot \mathrm{kg}^{-1}$, and the other one Low Squalene (LS), with squalene concentration below or equal to $5.0 \mathrm{~g} \cdot \mathrm{kg}^{-1}$, were fixed for classification tests into two squalene levels. These two classes were defined according to the squalene mean of the total sample set analyzed, whose value was this threshold. The technique performance assessment was by its success grade. This was expressed as the percentage of samples in which the predicted and actual classifications coincided.

\section{Results and Discussion}

\subsection{Olive Oil Spectrum}

232 Near-infrared spectra show various overlapping bands, due to the first and second 233 overtones and a combination of the fundamental vibrations, mainly carbon-hydrogen 234 (Shenk, Workman, \& Westerhaus, 2001). Assigning the major visible absorption bands 235 of olive oil was done by Moyano, Meléndez, Alba, \& Heredia (2008). Olive oil spectra 236 from the samples analyzed in this work, shown in Figure 2, are consistent with the 237 previously indicated reports. A first minor peak occured near $415 \mathrm{~nm}$. This area suits 238 the wavelengths of oil absorption for dark blue colored light. It could be due mainly to 239 carotenoids, as well as to pheophytin A, pheophorbide A and pyropheophytin A. A second peak was near $450 \mathrm{~nm}$, which corresponds to blue light absorption, a

241 characteristic of carotenoids. A third peak appeared around $670 \mathrm{~nm}$, which coincides with chlorophylls absorption (Moyano, Meléndez, Alba, \& Heredia, 2008). A broad absorbance band showed around $1220 \mathrm{~nm}$, probably due to second overtones of $\mathrm{C}-\mathrm{H}$ and $\mathrm{CH}=\mathrm{CH}-$ stretching vibrations of oil. A high intensity absorbance peak occured around $2300 \mathrm{~nm}$, caused by a combination of fundamental vibrations of the $\mathrm{C}-\mathrm{H}$ groups (Hourant, Baeten, Morales, Meurens, \& Aparicio, 2000). The squalene VIS/NIR spectra registered in this study are shown in Figure 3. The major differences in the spectrum of 
squalene with respect to olive oil correspond to the visible zone, since squalene is almost colorless. On the contrary, in the NIR region the peaks with squalene were practically the same as in olive oil, without remarkable differences. As a hydrocarbon molecule, a part of the squalene $\mathrm{C}-\mathrm{H}$ and $\mathrm{CH}=\mathrm{CH}-$ stretching vibrations may be overlapping those of triglycerides, whose structure is also carbon-hydrogen. However, the spatial configuration of the squalene molecule is clearly different from that of triglycerides due to its specific bonds. Moreover, the latter have oxygen, while squalene lacks this chemical element. Therefore, NIR absorption intensities may reflect such differences among different olive oils, despite the fact that they maybe not explicit in the spectrum shape.

\subsection{Population Characterization}

The values of the squalene reference analysis of the calibration and external validation sets are gathered in Table 1. As can be seen, a wide squalene variation integrates into the calibrations, ranging from $1.01 \mathrm{~g} \cdot \mathrm{kg}^{-1}$ to $10.15 \mathrm{~g} \cdot \mathrm{kg}^{-1}$. The statistical mean of the calibration sets analyzed was $5.02 \mathrm{~g} \cdot \mathrm{kg}^{-1}$ of squalene. The squalene content in the olive oils analyzed in this work showed a range even wider than those described in the literature (Tiscornia \& Evangelisti, 1982; Rao, Newmark \& Reddy, 1998; Owen, Mier, Giacosa, Hull, Spiegelhalder, \& Bartsh, 2000). This range reflects the extent of variation of squalene in this product, which accounts for the interest of distinguishing olive oils that are helpful to health due to their high squalene content.

\subsection{Principal Component Analysis}

271

The olive oils spectra PCA analysis of both spectrometers showed the absence of sample groups. The PCA of NIRS, shown in Figure 4, stands out for showing three samples widely separated from the major group. Two more samples appeared separated from the major group, both consistent with the HS class. The remaining samples did not show any consistent grouping trend. In the PCA of the VIS/NIRS spectra, shown in Figure 5, only two samples appear clearly separated. One of these samples matches the 
277 high squalene class and the other one matches the low squalene class. Therefore, the 278 PCA analysis of spectra did not show sample groups.

Figure 4

\subsection{Squalene PLS Models}

283 The absorbance data treated by $\mathrm{MN}$ and $\mathrm{D}_{1} \mathrm{SG}$ provided the best performance for 284 squalene content calibrations with both configurations, whose statistics are gathered in 285 Table 2. The same three samples which stood out in the PCA of the NIR spectra due to 286 their wide separation from the major group, they were identified as outliers in each 287 calibration and removed. The procedure for selecting the spectral variables provided a 288 wide range of contributing wavelengths. However, many of them did not contribute 289 positively to the PLS models, since their removal improved the calibration. The model $290 M_{l}$ provided $\mathrm{R}^{2} 0.86, \mathrm{R}_{\mathrm{CV}}^{2} 0.83$ and SEC 0.88 , while $M_{2}$ calibration statistics were $\mathrm{R}^{2}$ $2910.76, \mathrm{R}_{\mathrm{CV}}^{2} 0.72$ and SEC 1.19. The spectral windows and single wavelengths shared in 292 the $M_{1}$ model are shown in Figure 6. It is worth mentioning the matching among several 293 major wavelengths of $M_{l}$ with the major absorption area of the squalene spectra (Figure 294 3), corresponding to the $1700-1850 \mathrm{~nm}$ spectral window.

295 Figure 7 represents the regression for $M_{l}$. In these graphs, the horizontal line within a 296 certain wavelength shows zero contribution to the model.

\subsection{External Validation Exercises Using $M_{1}$}

301 One of the two samples separated from the major group in the PCA (Figure 4) 302 belonged to the validation set. This was separated, since it appeared in the validation as 303 an aberrant point, according to the criterion for outliers.. The statistics of the validation 
exercise are shown in Table 2. The dispersion plot of $V_{l}$ is shown in Figure 8. The squalene models performance is shown by the $r_{1}^{2}$ and $r_{2}^{2}$ values, 0.83 and 0.74 , from $V_{1}$ and $V_{2}$, respectively. The RPD values were 2.31 and 1.94 respectively for the same.

307 According to Fearn (2002), predictive models with RPD values between 2 and 10 are 308 suitable depending on the use they must carry out. Considering this, the $V_{l}$ prediction 309 exercise using $M_{1}$ suggests that this model is suitable for estimating the squalene 310 content in olive oils. Routine analysis of hydrocarbons in the olive oil industry is not 311 frequent, as it is not compulsory, thus the prediction technique here proposed is useful 312 for a preliminary characterization of olive oil on its squalene content.

\section{3.6. Classification Tests}

315 The $M_{1}$ PLS model was tested to distinguish two olive oil classes, HS and LS, according 316 to the threshold $5.0 \mathrm{~g} \cdot \mathrm{kg}^{-1}$. This technique provided $89.8 \%$ success in distinguishing 317 both classes. The results of this sorting test are shown in Table 3.

\section{Conclusions}

320 The wavelengths that contribute to a PLS model for squalene prediction have been 321 defined. The NIRS technique based on this PLS model has been proved useful for the

322 rapid estimation of olive oil squalene content. This model was used successfully to separate olive oil into two classes according to squalene content. The new technique proposed here provides an opportunity for characterizing olive oils based on their squalene content. This information has nutritional interest for the consumers. Besides, it constitutes a diversification opportunity for the olive oil industry. The wavelengths defined may allow choosing a suitable instrument for this purpose.

According to the test results, an error of about $10 \%$ can be expected in the separation of olive oil into two classes. The use of the proposed technique for estimating the squalene content of olive oil requires the calibration of a specific spectrophotometer, as well as establishing a periodic validation protocol. The proposed technique is to be used with 
332 olive oil directly, without neither solvents nor reagents, which makes it environmentally

333 friendly.

\section{Acknowledgments}

335 This research was made within the project Recupera 2020 1.4.4. We are thankful to the

336 European Regional Development Fund, as well to the Ministry of Economy and

337 Competitiveness of Spain and the Spanish Council for Scientific Research, for funding 338 this project.

\section{Bibliography}

340 Armenta, S., Garrigues, S., \& De la Guardia, M. (2007). Determination of edible oil 341 parameters by near infrared spectrometry. Analitical Chemical Acta, 596, 330-337.

342 Ben Hammouda, I., Zribi, A., Ben Mansour, A., Matthaus, B. \& Bouaziz, M. (2017).

343 Effect of deep-frying on 3-MCPD esters and glycidyl esters contents and quality control

344 of refined olive pomace oil blended with refined palm oil. European Food Research 345 and Technology 243, 7, 1219-1227.

346 Bendini, A., Cerretani, L., Di Virgilio, F., Belloni, P., Lercker, G., \& Gallina-Toschi, T. 347 (2007). In-process monitoring in industrial olive mill by means of FT-NIR. European 348 Journal of Lipid Science and Technology, 109, 498-504.

349 Cayuela, J. A. Moreda, W., \& García, J. M. (2013). Rapid determination of olive oil 350 oxidative stability and its major quality parameters using Vis/NIR transmittance 351 spectroscopy. Journal of Agricultural and Food Chemistry, 61, 8056-8062.

352 Cayuela, J. A., \& García, J. F. (2017). Sorting olive oil based on alpha-tocopherol and 353 total tocopherol content using Near-Infra-Red Spectroscopy (NIRS) analysis. Journal of 354 Food Engineering, 202, 79-88.

355 Civantos, L. (1999). Obtención del aceite de oliva. (2nd ed.). Madrid: Editorial Agrícola 356 Española, S.A. (Chapter 2).

357 European Commission (1991). Commission Regulation No 2568/91 of 11 July 1991 on 358 the characteristics of olive oil and olive-residue oil and on the relevant methods of 359 analysis. Official Journal of the European Communities, No L 248/1. 
360 Conte, L. S., Brussolo, G., Pizzale, L., Carazzolo, A., Meurens, M., \& Pavan, O. (2003).

361 Application of near infrared reflectance analysis to olive oil production quality control. Rivista Italiana delle Sostanze Grasse, 80, 213-217.

363 Costa, A. F., Coelho, M. J., Gambarra, F. F., Bezerra, S. R., Harrop, R. K., \& Ugulino, 364 M. C. (2008). NIR spectrometric determination of quality parameters in vegetable oils 365 using PLS and variable selection. Food Research International, 41, 341-348.

366 Eisner, J., Iverson, J. L., Mozingo, A. K., \& Firestone, D. (1965). Gas Chromatography 367 of unsaponifiable matter. III. Identification of hydrocarbons, aliphatic alcohols, 368 tocopherols, triterpenoid alcohols, and sterols present in olive oils. Journal of the 369 Association of Official Analitycal Chemists 48, 417-433.

370 Fearn, T. (2002). Assesing calibration. NIR News, 13, 12-14.

371 Giovenzana, V., Beghi, R., Civelli, R., Trapani, S., Migliorini, M., Cini, E., ... \& 372 Guidetti, R. (2017). Rapid determination of crucial parameters for the optimization of 373 milling process by using visible/near infrared spectroscopy in intact olives and olive 374 paste. Italian Journal of Food Science, 29, 357-369.

375 Hamadate N., Matsumoto, Y., Seto, K., Yamamoto, T., Yamaguchi. H., Nakagawa, T., ... \& Yazawa, K. (2015). Vascular effects and safety of supplementation with shark

377 liver oil in middle-aged and elderly males. Experimental and Therapeutic Medicine, 10, $378 \quad 641-646$.

379 Huang, S. R., Lin, Y. K., \& Fang, J. Y. (2009). Biological and Pharmacological 380 Activities of Squalene and Related Compounds: Potential Uses in Cosmetic 381 Dermatology. Molecules, 14, 540-554.

382 Hourant, P., Baeten, V., Morales, M. T., Meurens, M., \& Aparicio, R. (2000). Oil and 383 fat classification by selected bands of near-infrared spectroscopy. Applyed 384 Spectroscopy, 54, 1168-1174.

385 Karunathilaka, S. R., Kia, A. R. F., Srigley, C., Chung, J. K., Mossoba, M. M. (2016). 386 Nontargeted, Rapid Screening of Extra Virgin Olive Oil Products for Authenticity 
387 Using Near-Infrared Spectroscopy in Combination with Conformity Index and 388 Multivariate Statistical Analyses. Journal of Food Science, 81(10), C2390-C2397.

389 Lanzón, A., Albi, T., Cert, A., \& Gracián, J. (1994). The hydrocarbon fraction of virgin 390 olive oil and changes resulting from refining. Journal of the American Oil Chemists 391 Society, 71, 285-291.

392 Lasekan, J. B., Clayton, M. K., Gendron, A., \& Ney, D. M. (1990). Dietary olive and 393 safflower oil in promotion of DMBA-induced mammary tumorigenesis in rats. Nutrition 394 and Cancer, 13, 153-163.

395 Liu, G. C. K., Ahrens, E. H., Schreibman, P. H. \& Crouse, J. R. (1976). Measurement of 396 squalene in human tissues and plasma: validation and application. Journal of Lipid 397 Research 17, $38-45$.

398 Moreda, W., Pérez-Camino, M. C., \& Cert, A. (2004). Analysis of neutral lipids: 399 Unsaponifiables. In: M. Leo and L. Nollet (Eds.), Handbook of Food Analysis: Physical 400 characterization and nutrient analysis, $2^{\text {nd }}$ Edition (pp. 320-324). New York: Marcel 401 Dekker.

402 403 404 405

406

407

Moyano, M. J., Meléndez, A. J.; Alba, J., \& Heredia, F. J. (2008). A comprehensive study on the colour of virgin olive oils and its relationship with their chlorophylls and carotenoids indexes (I): CIEXYZ non-uniform colour space. Food Research International, 41, 505-512.

Nenadis, N., Tsimidou, M. (2017). Perspective of vibrational spectroscopy analytical methods in on-field/official control of olives and virgin olive oil. European Joural of Lipid Science and Technology, 119, 1600148. httplldoi.org.10.1002/ejlt.201600148.

Nergiz, C., \& Ünal, K. (1990). The effect of extraction systems on triterpene alcohols and squalene content of virgin olive oil. Grasas y Aceites, 41, 117-121.

Nergiz, C., \& Çelikkale, D. (2011). The effect of consecutive steps of refining on squalene content of vegetable oils. Journal of Food Science and Technology, 48, 382385 . 
414 Newmark, H. L. (1997). Squalene, olive oil, and cancer risk: A review and hypothesis.

415 Cancer Epidemiology, Biomarkers \& Prevention, 6, 1101-1103.

416 Owen, R. W., Mier, W., Giacosa, A., Hull, W. E., Spiegelhalder, B., \& Bartsh, H. 417 (2000). Phenolic compounds and squalene in olive oils: the concentration and 418 antioxidant potential of total phenols, simple phenols, secoiridoids, lignans and 419 squalene. Food and Chemical Toxicology, 38, 647-659.

420 Ostlund, R., Jr, M. D., Racette, S. B., \& Stenson, W. F. (2002). Effects of trace 421 components of dietary fat on cholesterol metabolism: phytosterols, oxysterols, and 422 squalene. Nutrition Reviews, 60, 349-359.

423 Psomiadou, E., \& Tsimidou, M., (1999). On the Role of Squalene in Olive Oil Stability. 424 Journal of Agricultural and Food Chemistry, 47, 4025-4032.

425 Rao, C. V., Newmark, K., \& Reddy, B. S. (1998). Chemopreventive effect of squalene 426 on colon cancer. Carcinogenesis, 19, 287-290.

427 Samaniego-Sánchez, C., Quesada-Granados, J. J., Lopez-Garcıa de la Serrana, H., \& 428 Lopez-Martınez, M. C. (2010). $\beta$-Carotene, squalene and waxes determined by 429 chromatographic method in picual extra virgin olive oil obtained by a new cold 430 extraction system. Journal of Food Composition and Analysis, 23, 671-676.

431 Shenk, J. S.; Workman, J. J.; Westerhaus, M. O. (2001). Application of NIR 432 spectroscopy to agricultural products. In: D. A. Burns, and C. W. Ciurcak (Eds.), 433 Handbook of Near Infrared Analysis, $2^{\text {nd }}$ Edition (pp. 419-474). New York: Marcel 434 Dekker.

435 Smith, T. J. (2000). Squalene: potential chemopreventive agent. Expert Opinion on 436 Investigational Drugs, 9, 1841-1848

437 Strandberg, T. E., Tilvis, R. S., \& Miettinen, T. A. (1990). Metabolic variables of 438 cholesterol during squalene feeding in humans: comparison with cholestyramine 439 treatment. Journal of Lipid Research 31, 1637-1643. 
440 Tiscornia, E. F. M., \& Evangelisti, F. (1982). Chemical compsqualenetion of olive oil 441 and its variations induced by refining. Rivista Italiana delle Sostanze Grasse, 59, 51944256.

443 Rao, C. V., \& Reddy, B. S. (1993). Modulating effect of amount and types of dietary fat 444 on ornithine decarboxylase, tyrsqualenene protein kinase and prostaglandins production 445 during colon carcinogenesis in male F344 rats. Carcinognesis, 14, 1327-1333.

446 Vazquez, L., Torres, C. F., Fornari, T., Senorans, F. J., \& Reglero, G. (2007). Recovery 447 of squalene from vegetable oil sources using countercurrent supercritical carbon dioxide 448 extraction. Journal of Supercritical Fluids, 40, 59-66.

$450 \quad$ Figure captions

451 Figure 1. Squalene structure.

452 Figure 2. Olive oil visible and near infrared spectra from the samples analyzed.

453 Figure 3. Visible and near infrared spectra of the squalene pettern (purity 98.0\%).

454 Figure 4. Principal Component Analysis of the near infrared spectra (1100-2300 nm) 455 from the analyzed olive oils.

456 Figure 5. Principal Component Analysis of the visible and near infrared spectra (350$4572500 \mathrm{~nm}$ ) from the analyzed olive oils.

458 Figure 6. Spectral variables contributing to the squalene near infrared model $\left(M_{1}\right)$.

459 Figure 7. Partial Least Squares quantitative squalene model $\left(M_{1}\right)$.

460 Figure 8. Prediction exercise of the olive oil squalene content $\left(V_{l}\right)$. 
Figure 1

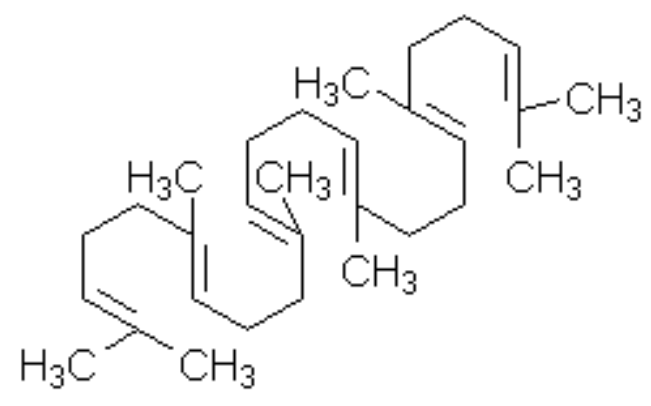


Figure 2

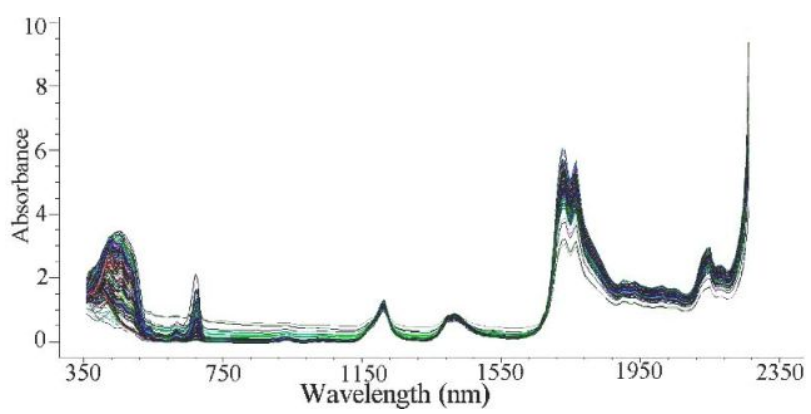


Figure 3

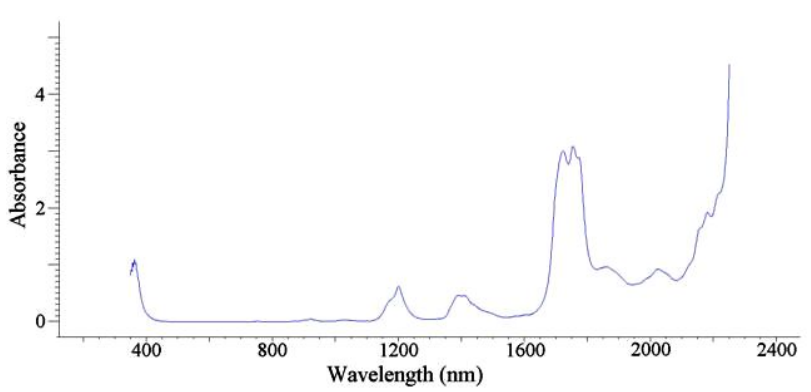


Figure 4

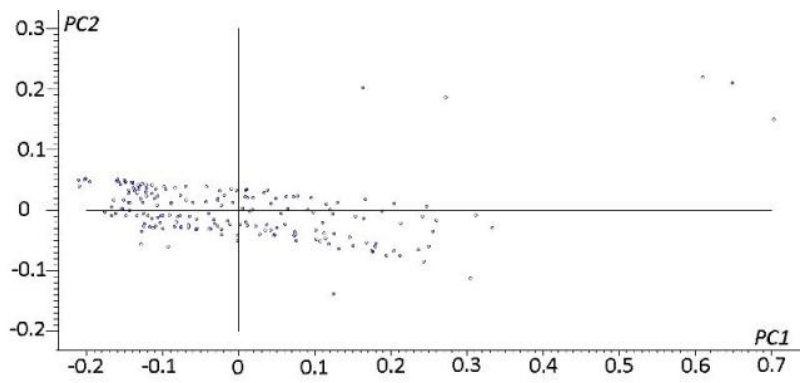


Figure 5

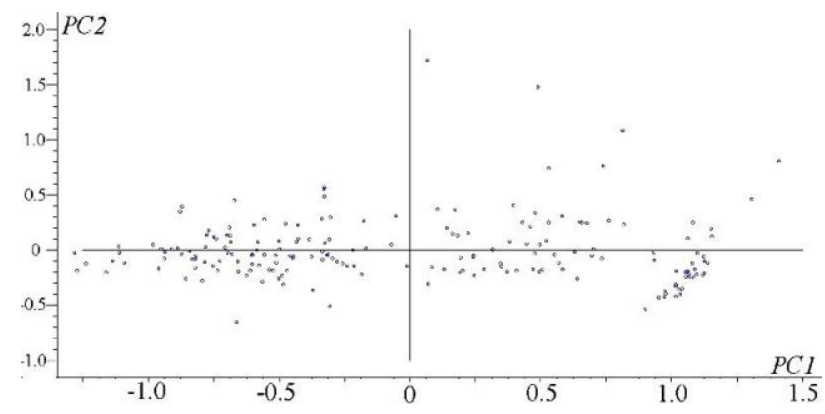


Figure 6

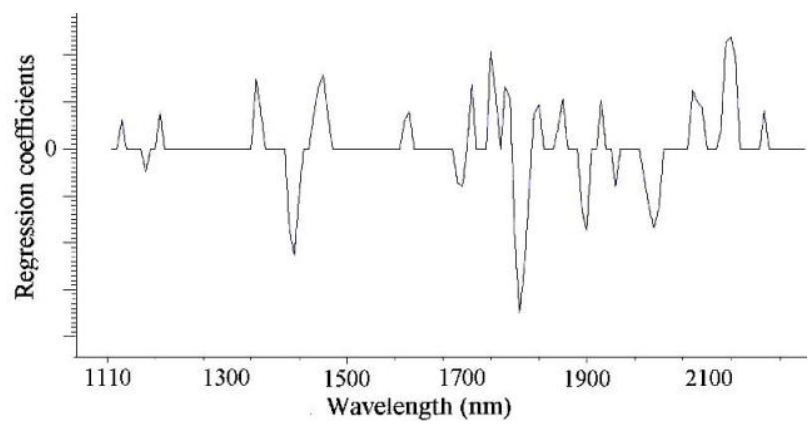


Figure 7

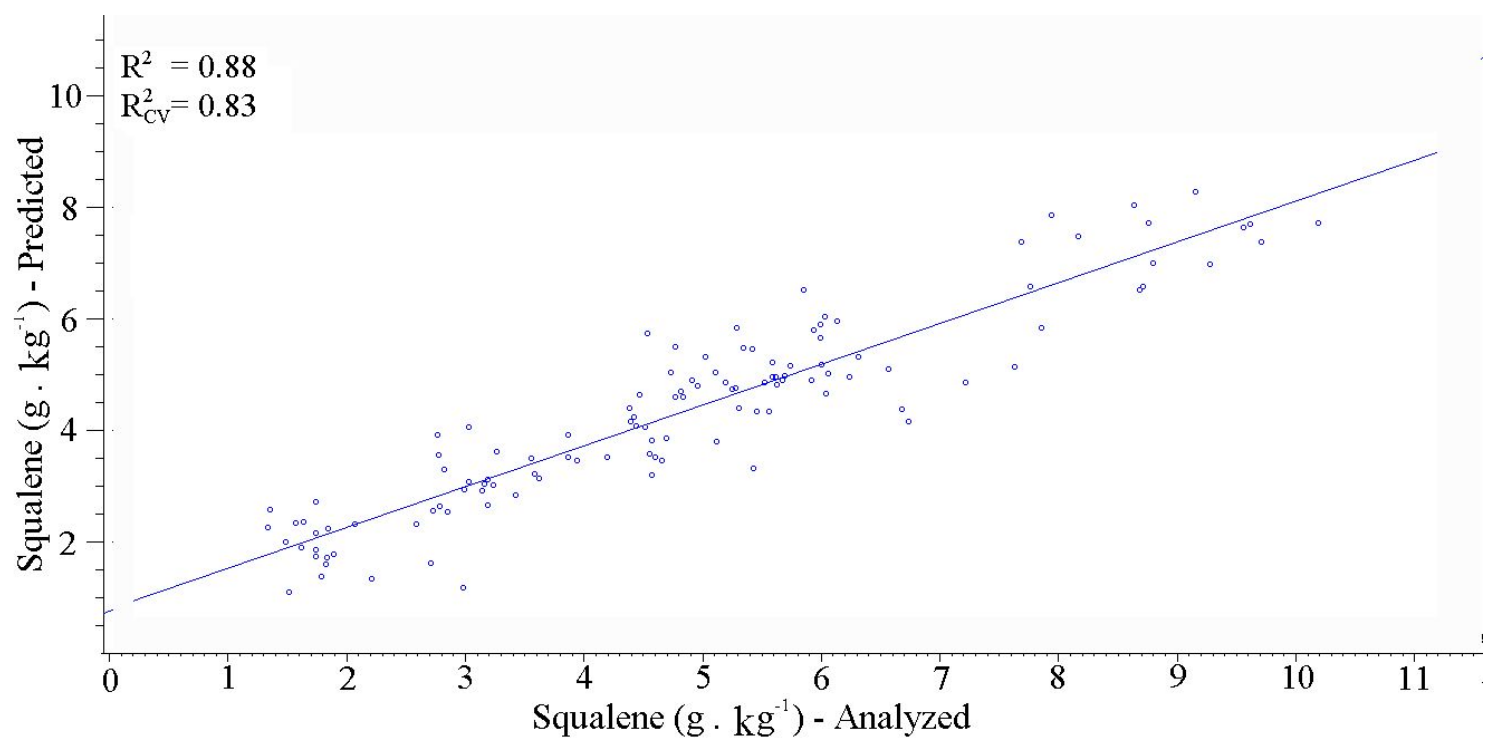


Figure 8

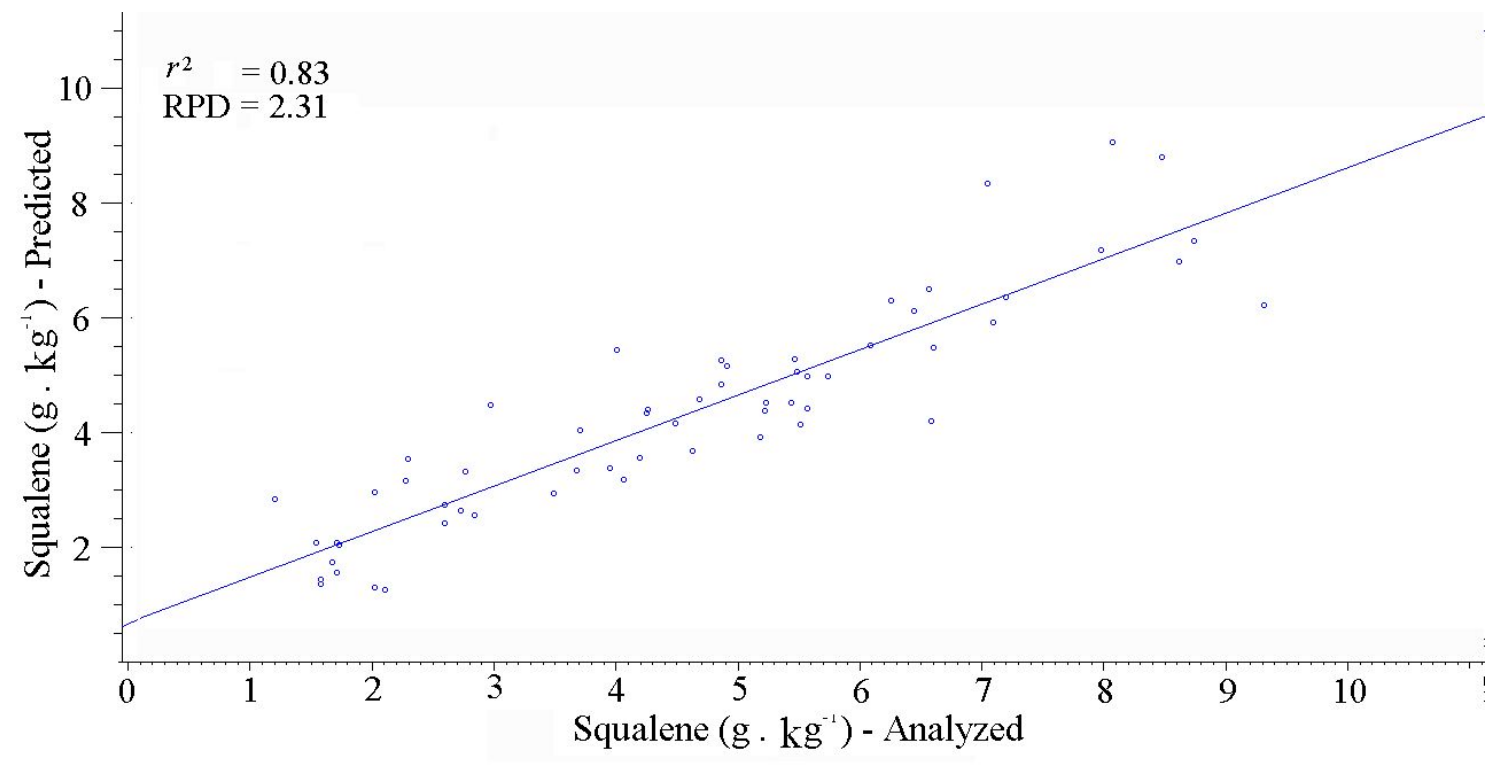


Table 1

\begin{tabular}{lrcc}
\hline $\mathbf{N}$ & $\overline{\mathbf{X}}$ & $\boldsymbol{\sigma}$ & Range \\
\hline \multicolumn{2}{c}{ Calibration } \\
$118 \quad 5.10$ & 2.19 & $1.01-10.15$ \\
Validation & & \\
$59 \quad 4.88$ & 2.33 & $1.22-10.02$ \\
\hline
\end{tabular}

Table 1. Statistics of the olive oil squalene content $\left(\mathrm{g}^{\mathrm{kg}} \mathrm{g}^{-1}\right)$ of the calibration and external validation sets. $N$, sample set size; $\bar{x}$, mean; $\sigma$, standard deviation. 
Table 2

\begin{tabular}{lcc|lcc}
\hline \multicolumn{3}{c|}{ Calibrations } & \multicolumn{3}{c}{ External validations } \\
\hline & NIRS $-M_{1}$ & VIS/NIRS $-M_{2}$ & & NIRS $-V_{1}$ & VIS/NIRS $-V_{2}$ \\
$\mathrm{~N}$ & 118 & 118 & $\mathrm{~N}$ & 59 & 59 \\
$\mathrm{PC}$ & 6 & 4 & $\mathrm{SEP}$ & 1.01 & 1.20 \\
$\mathrm{R}^{2}$ & 0.86 & 0.76 & $r^{2}$ & 0.83 & 0.74 \\
$\mathrm{R}^{2} \mathrm{CV}$ & 0.83 & 0.72 & RPD & 2.31 & 1.94 \\
$\mathrm{SEC}$ & 0.88 & 1.19 & & & \\
\hline
\end{tabular}

Table 2. Statistics of PLS models of the olive oil squalene content

NIRS, near infrared (1100-2300 nm); VIS/NIRS, visible and near infrared (350-2500 nm); $M_{1}$, NIRS model; $M_{2}$, VIS/NIRS model; $V_{1}$, NIRS model validation; $V_{2}$, VIS/NIRS model validation; $N$, size; PC, principal components; $R^{2}$, squared calibration regression coefficient; $R_{C V}$, squared calibration coefficient of cross validation; SEC, standard error of calibration; SEP, standard error of performance; $r^{2}$, squared validation regression coefficient; RPD, residual predictive deviation. 
Table 3

\begin{tabular}{lcc}
\hline Class & Actual & Predicted \\
\hline HS & 30 & 31 \\
LS & 29 & 28 \\
Total & 59 & 59 \\
\hline
\end{tabular}

Table 3. Olive oil sorting test according to squalene content using $M_{1}$ model (number of samples actual and predicted of each olive oil class).

HS, olive oil 'High squalene' (squalene $>5 \mathrm{~g} \cdot \mathrm{kg}^{-1}$ ); LS, olive oil 'Low squalene' (squalene $\leq 5 \mathrm{~g} \cdot \mathrm{kg}^{-1}$ ). 


\begin{tabular}{|c|c|c|c|}
\hline № & Olive oil class & Commercial names & Variety, blend, coupage, or acidity \\
\hline 1 & & Acanto & \\
\hline 2 & & Castillo de Canena & \\
\hline 3 & & $\tilde{N}$ Organic & \\
\hline 4 & & Castillo de Tabernas & \\
\hline 5 & & Melgarejo Picual & Picual \\
\hline 6 & & Spirito Santo & \\
\hline 7 & & Rincón de la Subbética & \\
\hline 8 & & La Solana 2 & \\
\hline 9 & & Marqués de Griñón & \\
\hline 10 & & Románico & \\
\hline 11 & & Alma Oliva & \\
\hline 12 & & L’Estornell & Arbequina \\
\hline 13 & & Basilipo & \\
\hline 14 & & Melgarejo Arbequina & \\
\hline 15 & & La Torre & \\
\hline 16 & & La Cultivada & Hojiblanca \\
\hline 17 & & Melgarejo Hojiblanca & \\
\hline 18 & & La Española & \\
\hline 19 & & Vega Oliva & Manzanillla \\
\hline 20 & & El Lagar del Soto & Manzanilla Cacereña \\
\hline 21 & & Changlot Real & Changlot Real \\
\hline 22 & & Acrópolis & Koroneiki \\
\hline 23 & EVOO & Supremo & Arbosana \\
\hline 24 & & Morellana & Picudo \\
\hline 25 & Gourmet trade & De Ortegas & Cornicabra \\
\hline 26 & & Melgarejo Frantoio & Frantoio \\
\hline 27 & & Oleo Aureo & Pico Limón \\
\hline 28 & & Duque de Baena & Undefined \\
\hline 29 & & Almenara Premium & Undefined \\
\hline 30 & & Molino de Gines & Undefined \\
\hline 31 & & Acanto + Supremo & \\
\hline 32 & & Spirito Santo + Rincón de la Subbética & \\
\hline 33 & & Spirito Santo + La Solana 2 & Picual blend $(1 / 2+1 / 2)$ \\
\hline 34 & & Castillo de Canena + La Torre & \\
\hline 35 & & Castillo de Tabernas + Castillo Canena & \\
\hline 36 & & L’Estornell +Alma Oliva & \\
\hline 37 & & L’Estornell + Basilipo & \\
\hline 38 & & L'Estornell + Melgarejo Arbequina & Arbequina blend $(1 / 2+1 / 2)$ \\
\hline 39 & & L’Estornell + Románico & \\
\hline 40 & & La Torre + La Cultivada & \\
\hline 41 & & La Torre + Melgarejo Hojiblanca & Hojiblanca blend $(1 / 2+1 / 2)$ \\
\hline 42 & & La Cultivada + Melgarejo Hojiblanca & \\
\hline 43 & & La Española + Vega OLiva & Manzanilla blend $(1 / 2+1 / 2)$ \\
\hline 44 & & El Lagar del Soto + La Española & Manzanilla blend $(1 / 2+1 / 2)$ \\
\hline 45 & & Núñez de Prado + Acrópolis & Picual+Picuda+Hojiblanca+Manzanill \\
\hline
\end{tabular}




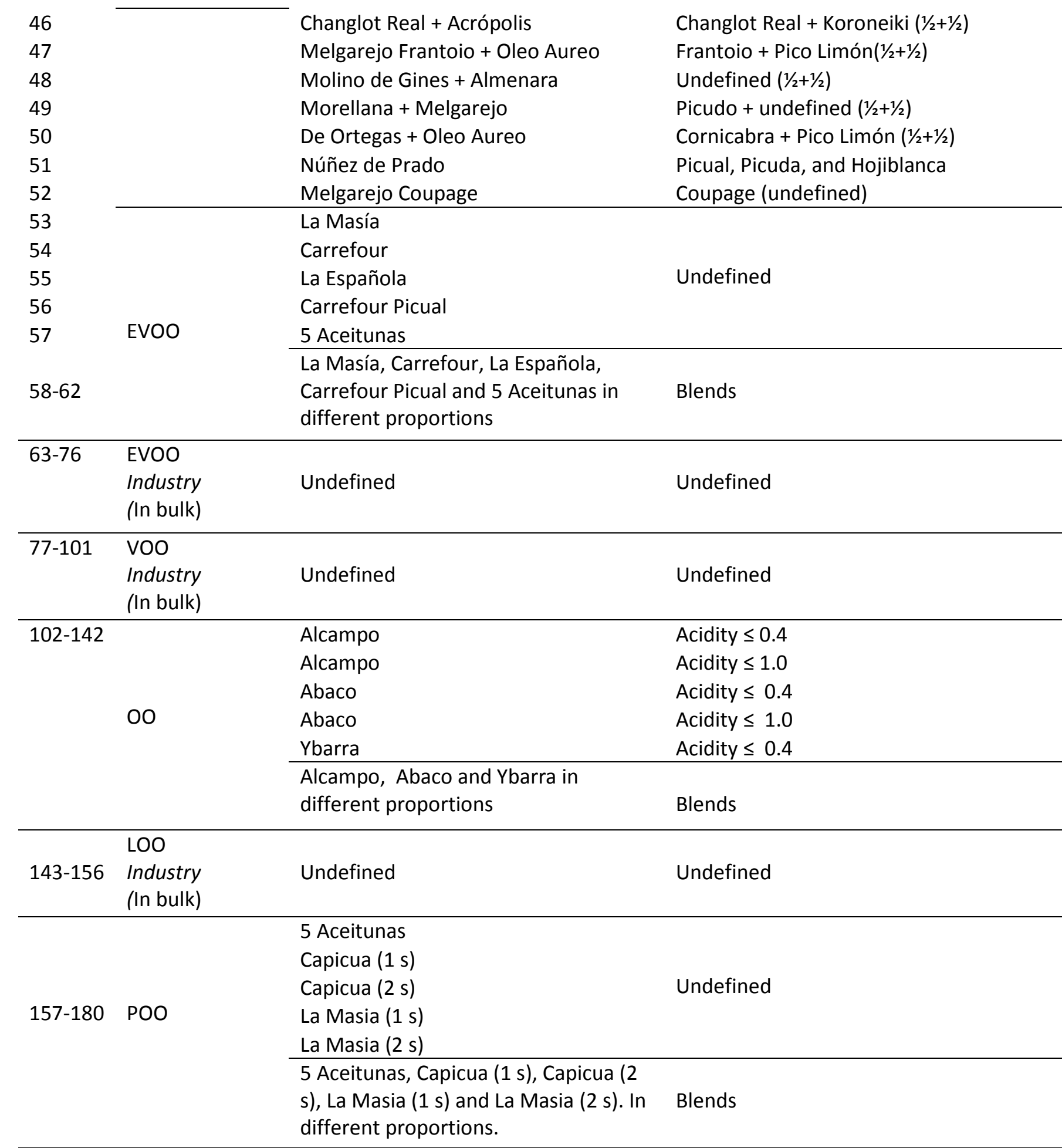

Table S1. Characteristics of the olive oil samples.

EVOO, extra virgin olive oil; VOO, virgin olive oil; OO, olive oil; LOO; lampante olive oil; POO, pomace olive oil; s, samples. 